\title{
CIP-36, a novel topoisomerase II-targeting agent, induces the apoptosis of multidrug-resistant cancer cells in vitro
}

\author{
BO CAO ${ }^{1}$, HONG CHEN $^{2}$, YING GAO $^{1}$, CONG NIU $^{1}$, YUAN ZHANG $^{3}$ and LING LI $^{1}$ \\ ${ }^{1}$ Logistics University of Chinese People's Armed Police Forces; ${ }^{2}$ Tianjin Key Laboratory \\ of Cardiovascular Remodeling and Target Organ Injury, Tianjin, Hebei 300162; \\ ${ }^{3}$ Armed Police Corps in Xinjiang Southern Command Hospital, Urumqi, Xinjiang 830091, P.R. China
}

Received September 28, 2014; Accepted January 8, 2015

DOI: $10.3892 /$ ijmm.2015.2068

\begin{abstract}
The need to overcome cancer multidrug resistance (MDR) has fueled considerable interest in the development of novel synthetic antitumor agents with cytotoxicity against cancer cell lines with MDR. In this study, we aimed to investigate CIP-36, a novel podophyllotoxin derivative, for its inhibitory effects on human cancer cells from multiple sources, particularly cells with MDR in vitro. The human leukemia cell line, K562, and the adriamycin-resistant subline, K562/A02, were exposed to CIP-36 or anticancer agents, and various morphological and biochemical properties were assessed by Hoechst 33342 staining under a fluorescence microscope. Subsequently, cytotoxicity, cell growth curves and the cell cycle were analyzed. Finally, the effects of CIP-36 on topoisomerase II $\alpha$ (Topo II $\alpha$ ) activity were determined. Treatment with CIP-36 significantly inhibited the growth of the K562 and MDR K562/A02 cells. Our data demonstrated that CIP-36 induced apoptosis, inhibited cell cycle progression and inhibited Topo II $\alpha$ activity. These findings suggest that CIP-36 has the potential to overcome the multidrug resistance of K562/A02 cells by mediating Topo II $\alpha$ activity.
\end{abstract}

\section{Introduction}

Multidrug resistance (MDR), a cross-resistance of cancer cells to seemingly unrelated drugs, such as anthracyclines vinca alkaloids (doxorubicin and daunorubicin), epipodophyllotoxins, (vincristine and vinblastine) and taxanes (taxol and taxotere), is a major clinical concern in the treatment of human cancers with conventional chemotherapeutic drugs (1).

Topoisomerase II (Topo II) poisons widely used in clinical practice, such as etoposide, adriamycin (ADM)

Correspondence to: Dr Hong Chen, Tianjin Key Laboratory of Cardiovascular Remodeling and Target Organ Injury, Tianjin, 220 Cheng-Lin Road, Hebei 300162, P.R. China

E-mail: chenhongtian06@163.com

Dr Yuan Zhang, Armed Police Corps in Xinjiang Southern Command Hospital, No. 164, Xi-yu Road, Urumqi, Xinjiang 830091, P.R. China E-mail: zhangyuanmedsci@163.com

Key words: CIP-36, podophyllotoxin derivative, topoisomerase, apoptosis, multidrug resistance, Bcl-2 family and their analogues often induce dose-limiting toxicity and MDR, resulting in treatment failure after the initial effective therapy $(2,3)$. Therefore, increasing research has focused on the development of novel Topo II-targeting drugs, with the aim to overcome current hurdles (4-6).

Although reversal agents have been assessed for their efficacy against cancers with MDR, the majority have shown little or no therapeutic potential due to their high toxicity in vivo at the doses required to reverse MDR, as observed with verapamil (7). Over the past few years, podophyllotoxin derivatives have been widely used as cancer chemotherapeutic agents (8). For instance, etoposide, a low toxicity semisynthetic podophyllotoxin analogue, has been utilized for the treatment of a broad spectrum of tumors, for its Topo II-targeting properties $(9,10)$. The suppression of Topo II activity by Topo II-targeting drugs, such as etoposide and ADM, can lead to double-stranded DNA breaks $(11,12)$. In addition, other newly developed derivatives (e.g., NPF and GL-331) (13-15) which have displayed better pharmacology profiles are currently being evaluated in clinical trials (16). However, compared to many previously described drugs, they have not shown sufficient potency in the treatment of cancers with MDR. Recently, a novel podophyllotoxin derivate, CIP-36 (Fig. 1), was synthesized in our laboratory and presented the advantages of effectiveness, stability and low toxicity. In this study, we aimed to investigate CIP-36 for its effects on cancer cells with MDR. In vitro enzymatic assay demonstrated the effectiveness of CIP-35 in inhibiting Topo II $\alpha$ activity. CIP-36 inhibited the proliferation of multiple cancer cells, including multidrug-resistant K562/A02 cells, suggesting that it has the potential for use as an optional chemical agent in the treatment of cancers with MDR.

\section{Materials and methods}

Anticancer drugs. CIP-36 (purity >98\%) was synthesized in the laboratory of Professor Hong Chen by Dr Pengfei Yu. Its molecular structure is illustrated in Fig. 1. ADM was purchased from Shenzhen Wanle Pharmaceutical Co., Ltd. (Shenzhen, China) and etoposide (VP-16) was from Jiangsu Hengrui Medicine Co., Ltd. (Jiangsu, China).

Cells. The human leukemia cell line, K562, and the ADM subline, K562/A02, were obtained from the Institute of Hematology and Blood Disease Hospital, Chinese Academy of Medical Sciences 
and Peking Union Medical College (Beijing, China). Other cell lines, including human uterine cervical adenocarcinoma cells (HeLa), human breast adenocarcinoma cells (MCF-7), human oral squamous carcinoma cells (KB) and their multidrug resistant counterpart (KBv200 cells), human osteosarcoma cells (HOS), human colon carcinoma cells (LoVo), human hypertrophic scar fibroblasts (FBs) and human vascular endothelial cells (VECs) were supplied by the Institute of Materia Medica, Chinese Academy of Medical Sciences and Peking Union Medical College (Beijing, China). These cell lines were cultured in RPMI-1640 (Sigma-Aldrich, St. Louis, MO, USA) containing $10 \%$ heat-inactivated fetal bovine serum, penicillin $(100 \mathrm{U} / \mathrm{ml})$ and streptomycin $(100 \mu \mathrm{g} / \mathrm{ml})$ in a humidified environment with $5 \% \mathrm{CO}_{2}$ at $37^{\circ} \mathrm{C}$. The $\mathrm{K} 562 / \mathrm{A} 02$ cells were stable and cultured in medium containing $1 \mu \mathrm{g} / \mathrm{ml} \mathrm{ADM}$ in order to obtain the stability of drug resistance. $\mathrm{ADM}(10$ and $0.5 \mu \mathrm{g} / \mathrm{ml})$ was used to measured the cell growth curve. The KBv200 cells were stable and cultured in medium containing $200 \mathrm{nmol} / \mathrm{l}$ vincristine (Shenzhen Main Luck Pharmaceuticals Inc., Wanleyaoye, Shenzhen, China) in order to obtain the stability of drug resistance. The KBv200 cells were used to measured the cytotoxic effects of CIP-36. The drugs were removed 2 weeks prior to the experiment.

Cytotoxicity assays. Cytotoxicity was assessed by sulforhodamine B (SRB) or 3-(4,5-dimethylthiazol-2-yl)2,5-diphenyltetrazolium bromide (MTT) (Sigma-Aldrich) cytotoxicity assay in 96-well microtiter plates as previously described $(17,18)$. Briefly, the medium was replaced with fresh medium containing $0.5 \mathrm{mg} / \mathrm{ml}$ of MTT. After $4 \mathrm{~h}$ of incubation at $37^{\circ} \mathrm{C}$, the cellular formazan product was dissolved in dimethylsulfoxide (DMSO) and the absorbance was measured at a wavelength of $570 \mathrm{~nm}$ using a spectrophotometer (PerkinElmer Inc., Boston, MA, USA).

Cell growth curve following treatment with CIP-36. The K562 and K562/A02 cells in the log phase were seeded in 96-well plates at a density of $8,000 \mathrm{cells} / \mathrm{ml}$. The cells were then treated with various concentrations CIP-36 in RPMI-1640. The number of viable cells was quantified by SRB assay every $24 \mathrm{~h}$ for 6 consecutive days in order to establish the growth curve in vitro.

Assessment of apoptosis by Hoechst 33342 and propidium iodide (PI) staining. The cells were exposed to CIP-36 at various concentrations for $24 \mathrm{~h}$, washed twice with phoshate-buffered saline (PBS) and fixed with $4 \%$ formaldehyde for $10 \mathrm{~min}$. The fixed cells were then washed and stained with $10 \mu \mathrm{g} / \mathrm{ml}$ of Hoechst 33342 and PI for $10 \mathrm{~min}$. The cells were examined under a fluorescence microscope (XSZ-D2; Olympus, Tokyo, Japan).

Cell cycle analysis by flow cytometry. The K562/A02 cells $\left(1 \times 10^{6}\right)$ were treated with various concentrations of CIP-36 for 6, 12 and $24 \mathrm{~h}$ at $37^{\circ} \mathrm{C}$, harvested, washed with PBS and fixed with $70 \%$ ethanol. The fixed cells were kept overnight at $-20^{\circ} \mathrm{C}$ and washed with PBS prior to treatment with $50 \mu \mathrm{g} / \mathrm{ml}$ PI solution in PBS, containing RNase $(50 \mu \mathrm{g} / \mathrm{ml})$. Cell cycle analysis was carried out on an Epics XL flow cytometer (Beckman Coulter, Miami, FL, USA).

Topo II $\alpha$ DNA cleavage assay. Recombinant DNA Topo II $\alpha$ was cloned and purified as previously described (19). DNA cleavage<smiles></smiles>

Figure 1. Chemical structure of CIP-36.

assays were carried according to the procedure described in the study by Lemke et al (20) with minor modifications. The total volume reaction mixture of $20 \mu 1$ contained $20 \mathrm{mM}$ Tris/ $\mathrm{HCl}$, $\mathrm{pH}$ 7.5, $7.5 \mathrm{mM} \mathrm{MgCl}_{2}, 0.5 \mathrm{mM}$ dithiothreitol, $150 \mathrm{mM} \mathrm{KCl}$, $1 \mathrm{mM}$ ATP and 200 ng of pBR322 DNA (Toyobo Co. Ltd., Japan). The reaction was inititated by the addition of 5 units of DNA Topo II $\alpha$ followed by incubation at $30^{\circ} \mathrm{C}$ for $10 \mathrm{~min}$. One unit of enzyme activity was defined as the amount of enzyme decatenating $0.2 \mu \mathrm{g}$ of kinetoplast DNA in $30 \mathrm{~min}$ at $37^{\circ} \mathrm{C}$, according to the manufacturer's instructions (T8944; SigmaAldrich). The reactions were terminated by the addition of sodium dodecyl sulfate and proteinase $\mathrm{K}$ at final concentrations of $0.35 \%$ and $0.3 \mathrm{mg} / \mathrm{ml}$, respectively. After an additional incubation for $60 \mathrm{~min}$ at $37^{\circ} \mathrm{C}, 5 \mu \mathrm{l}$ of gel loading buffer were added to each reaction mixture. The samples were loaded on $1 \%$ agarose gels containing $0.5 \mu \mathrm{g} / \mathrm{ml}$ ethidium bromide and separated for $18 \mathrm{~h}$ in TBE buffer at $0.5 \mathrm{~V} / \mathrm{cm}$. The gels were then destained in distilled water and photographed using a gel-imaging system (Bio-Rad, Hercules, CA, USA). The percentage of supercoiled DNA in each sample was determined using Quantity One Image software (Bio-Rad), and the relative activity of Topo II $\alpha$ in the drug-treated cells, as previously described (21).

Statistical analysis. The statistical package SPSS 17.0 (SPSS, Chicago, IL, USA) was used for all analyses. Data are presented as the means \pm standard deviation (SD) and all the experiments were repeated at least 3 times. Statistical significance between 2 groups was determined by the Student's t-test. For 3 groups or more, one-way analysis of variance (ANOVA) was used and post hoc analysis by least significant difference. A value of $\mathrm{P}<0.05$ was considered to indicate a statistically significant difference.

\section{Results}

Effects of CIP-36 on the proliferation of human cancer and normal cells. First, CIP-36 was compared to ADM for its efficacy. As shown in Table I, the K562 cells were sensitive to all drugs tested. However, the K562/A02 cells were resistant to ADM, whereas no cross-resistance to CIP-36 was observed. Indeed, a resistance index (RI) of 3.27 was obtained 
Table I. Cytotoxic activity of ADM, CIP-36 and VP-16 against K562 and K562/A02 cells by SRB assay.

\begin{tabular}{lccc}
\hline & \multicolumn{3}{c}{$\mathrm{GI}_{50}$} \\
\cline { 2 - 4 } Cancer cell lines & $\begin{array}{c}\mathrm{ADM} \\
(\mu \mathrm{g} / \mathrm{ml})\end{array}$ & $\begin{array}{c}\mathrm{VP}-16 \\
(\mu \mathrm{mol} / \mathrm{l})\end{array}$ & $\begin{array}{c}\mathrm{CIP}-36 \\
(\mu \mathrm{mol} / \mathrm{l})\end{array}$ \\
\hline K562 & $0.21 \pm 0.17$ & $1.08 \pm 0.42$ & $1.02 \pm 0.58$ \\
K562/A02 & $14.28 \pm 1.21$ & $36.56 \pm 2.31$ & $3.34 \pm 1.12$ \\
RI & 68 & 33.85 & $\mathbf{3 . 2 7 ^ { \mathrm { a } }}$ \\
\hline
\end{tabular}

Data are presented as the means $\pm \mathrm{SD} ; \mathrm{n} \geq 3$. ADM, adriamycin; $\mathrm{VP}-16$, etoposide; SRB, sulforhodamine B; $\mathrm{GI}_{50}$, concentration for $50 \%$ of maximal inhibition of cell proliferation; RI, resistance index. Numbers in bold indicate statistical significance. ${ }^{\mathrm{a}} \mathrm{P}<0.05$ compared with VP-16 group.

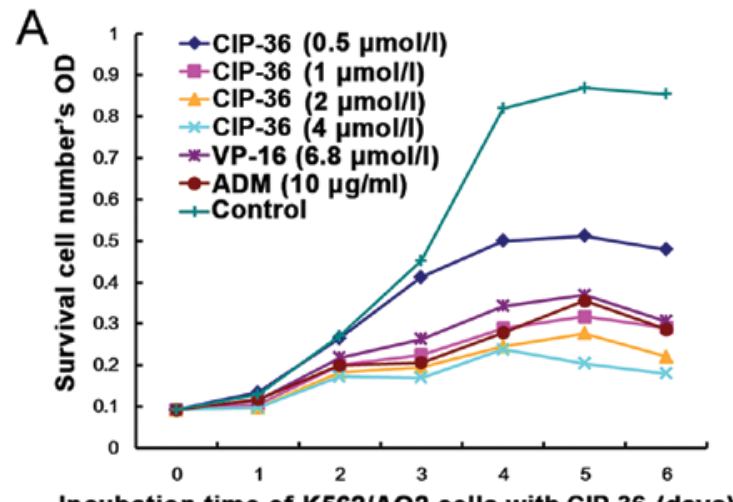

Incubation time of K562/AO2 cells with CIP-36 (days)

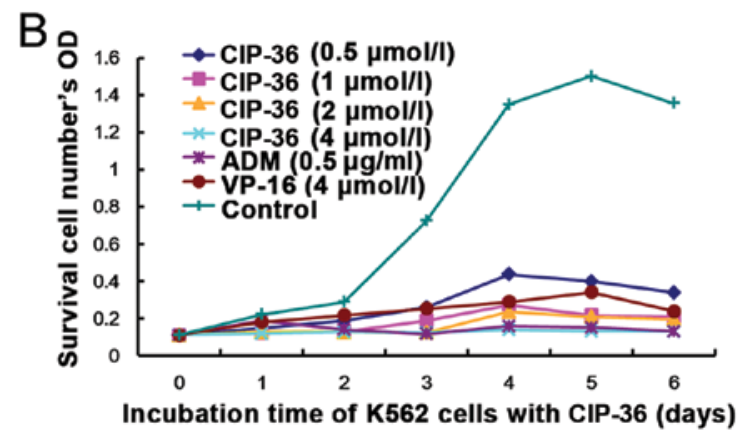

Figure 2. Effects of CIP-36 on cell growth and viability are exerted in a timeand concentration dependent manner. (A) K562/A02 cells and (B) K562 cells were treated with dimethylsulfoxide (DMSO; control), adriamycin (ADM), VP-16 or CIP-36 at various concentrations. The viable cells were accessed each day following treatment by MTT assay.

for CIP-36, markedly lower than the RI values obtained for ADM (RI of 68) and VP-16 (RI of 33.85). Subsequently, the anti-proliferative activity of CIP-36 was further assessed in 8 human cancer cell lines. CIP-36 showed a broad-spectrum anti-proliferative activity, with rather similar inhibitory properties against various human cancer cells: the concentration for $50 \%$ of maximal inhibition of cell proliferation $\left(\mathrm{GI}_{50}\right)$ or half maximal inhibitory concentration $\left(\mathrm{IC}_{50}\right)$ values ranged from 0.14-3.34 $\mu \mathrm{mol} / 1$ for CIP-36, generally lower than those of etoposide (VP-16; 0.45-34.76 $\mu \mathrm{mol} / \mathrm{l})$. Of note, as observed for the K562/A02 cells, the KBv200 cells were resistant to etopo-
Table II. Cytotoxic effects of CIP-36 on different cell lines.

\begin{tabular}{lrr}
\hline Cancer cells & VP-16 & \multicolumn{1}{c}{ CIP-36 } \\
\hline KB & $1.71 \pm 0.04$ & $1.41 \pm 0.06$ \\
KBv200 & $\mathbf{1 2 . 1 \pm \mathbf { 1 . 2 3 }}$ & $\mathbf{2 . 0 6 \pm 0 . 3 8}$ \\
HeLa & $2.56 \pm 0.53$ & $1.96 \pm 0.46$ \\
MCF-7 & $8.61 \pm 0.88$ & $3.13 \pm 0.22$ \\
LoVo & $2.38 \pm 0.76$ & $2.01 \pm 0.36$ \\
HOS & $2.32 \pm 0.25$ & $3.39 \pm 0.85$ \\
VECs & $55.57 \pm 1.78$ & $15.11 \pm 0.77$ \\
FBs & $57.87 \pm 3.45$ & $26.08 \pm 2.29$
\end{tabular}

Half maximal inhibitory concentration $\left(\mathrm{IC}_{50}\right)$ values $(\mu \mathrm{mol} / \mathrm{l})$ were determined by MTT assay. Data are the means \pm SD from at least 3 independent replicates. VP-16, etoposide. Numbers in bold indicate statistical significance. ${ }^{\mathrm{a}} \mathrm{P}<0.05$ compared with $\mathrm{KBv} 200$ cell line $\mathrm{IC}_{50}$ values of VP-16.

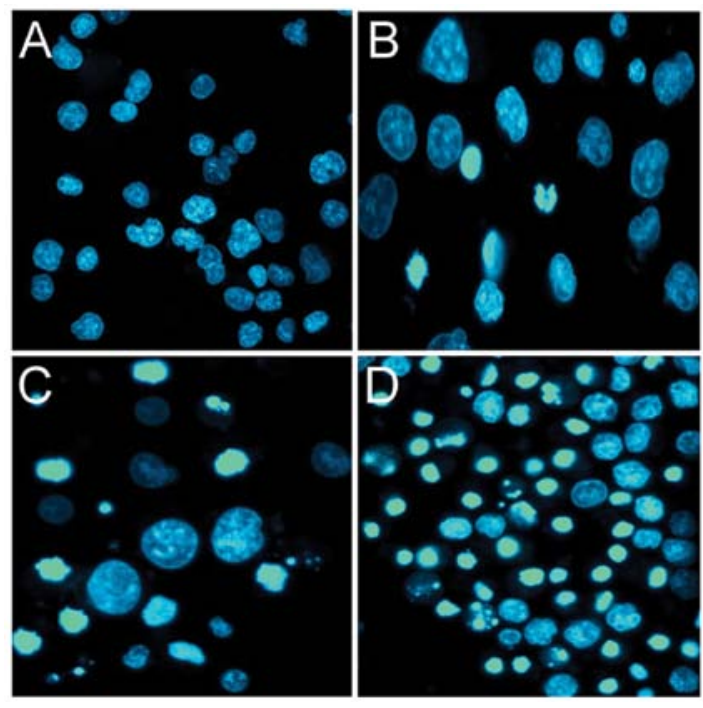

Figure 3. Nuclear morphological changes in the K562/A02 cells treated with CIP-36 at various doses. Cells treated with CIP-36 were stained with Hoechst 33342 and observed under a fluorescence microscope. Cells undergoing apoptosis showed condensed chromosome structures. Treatment with (A) $0.1 \%$ dimethylsulfoxide (DMSO); (B) $1 \mu \mathrm{mol} / 1$ of CIP-36 for $24 \mathrm{~h}$; (C) $2 \mu \mathrm{mol} / 1$ of CIP-36 for $24 \mathrm{~h}$; (D) $4 \mu \mathrm{mol} / 1$ of CIP-36 for $24 \mathrm{~h}$.

side, but not CIP-36 (Table II). Importantly, CIP-36 displayed less cytotoxicity towards normal human cell lines (fibroblasts, VECs), with significantly higher $\mathrm{IC}_{50}$ values recorded for the normal cells in comparison with the cancer cells. Furthermore, we demonstrated that the effects of CIP-36 on the K562 and K562/A02 cells occurred in a concentration- and time-dependent manner, confirming the above-mentioned results (Fig. 2).

Effects of CIP-36 on the apoptosis of K562/A02 cells. To determine the mechanisms of the CIP-36-induced cytotoxic effects, we evaluated the ability of the compound to induce apoptosis, using Hoechst 33342 staining and flow cytometry. We found that CIP-36 induced morphological changes, characteristic of apoptosis in the K562/A02 cells, such as chromosome condensation (Fig. 3). Flow cytometric analysis of the K562/A02 cells 


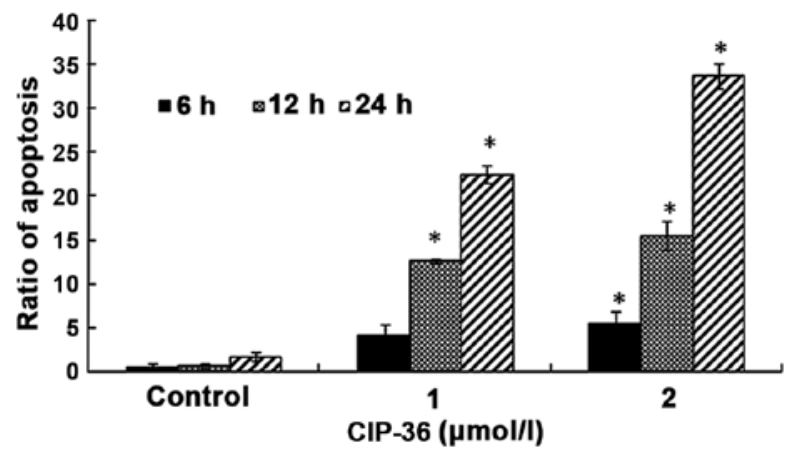

Figure 4. Percentage of apoptotic K562/AO2 cells following treatment with CIP-36. Treated cells were stained with propidium iodide (PI) and analyzed by flow cytometry. Apoptotic cell populations were measured as cells containing less than diploid DNA contents. Quantitative results from at least 3 independent experiments are presented. Data are the means $\pm \mathrm{SD}$. ${ }^{*} \mathrm{P}<0.05$ compared with the control group.
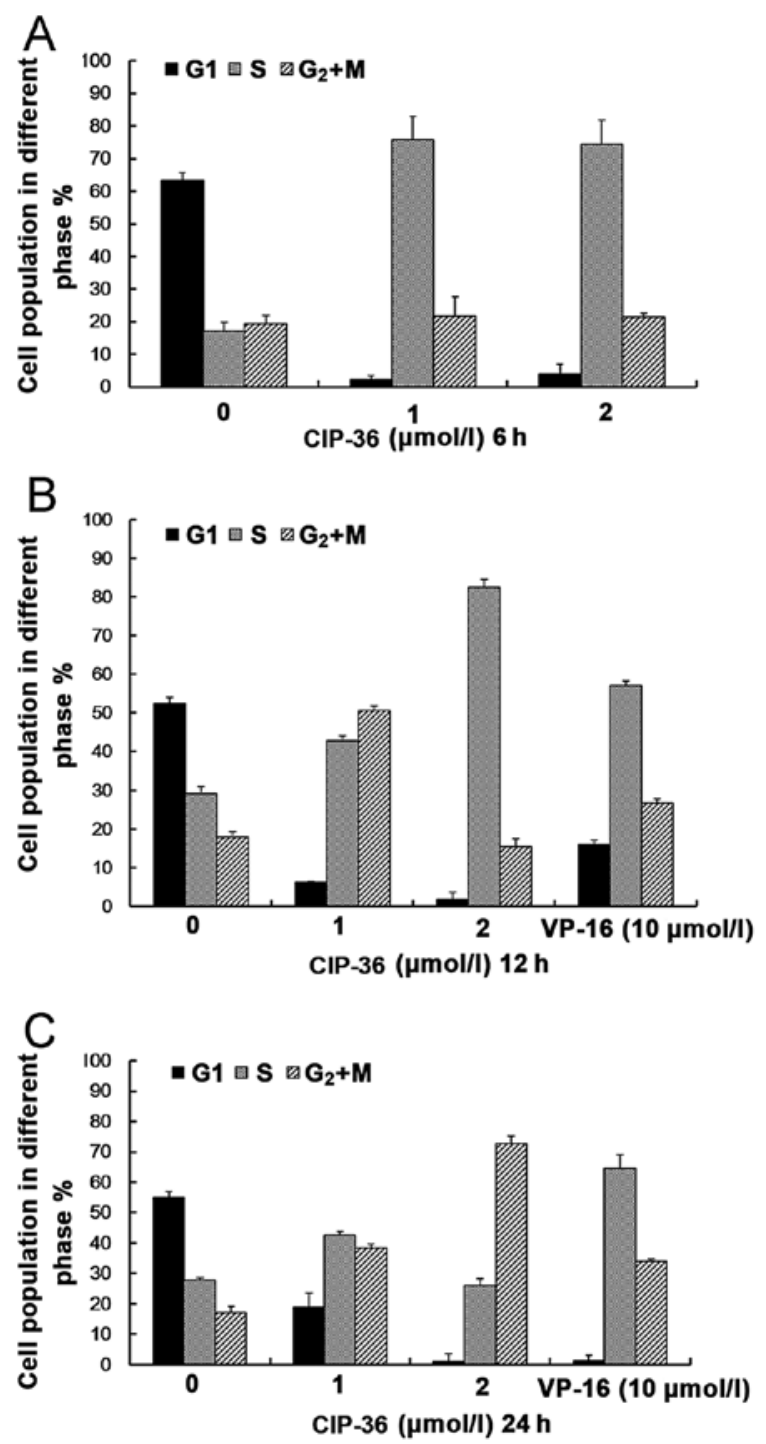

Figure 5. Alterations in cell cycle phase distribution in response to CIP-36 treatment in K562/A02 cells. The cell populations in different stages of the cell cycle were measured using propidium iodide (PI) staining and flow cytometric analysis. (A) Cell cycle fraction of K562/A02 cells exposed to $0.1 \%$ dimethylsulfoxide (DMSO) or CIP-36 for $6 \mathrm{~h}$. (B) Cell cycle fraction of K562/A02 cells exposed to $0.1 \%$ DMSO or $10 \mu \mathrm{mol} / 1 \mathrm{VP}-16$ or exposed to CIP-36 for $12 \mathrm{~h}$. (C) Cell cycle fraction of K562/A02 cells exposed to $0.1 \%$ DMSO or $10 \mu \mathrm{mol} / 1$ VP-16 or exposed to CIP-36 for $24 \mathrm{~h}$.
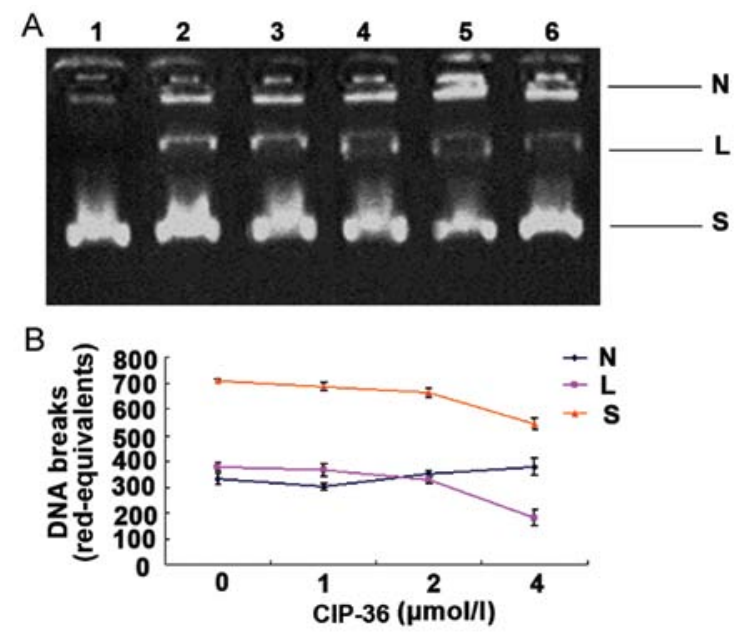

Figure 6. Effects of CIP-36 on DNA cleavage by topoisomerase II $\alpha$ (Topo II $\alpha$ ). (A) Representative images of agarose gels are shown. Supercoiled pBR322 DNA was incubated with 4 units of Topo II $\alpha$ in the absence or presence of drugs. Lanes 1, DNA substrate; lane 2, reaction mixture containing enzyme but no drugs; lanes 3-5, reaction in the presence of 1, 2 and $4 \mu \mathrm{M}$ CIP-36; lane $6,10 \mu \mathrm{M}$ etoposide. (B) The rad-equivalents of the supercoiled form, nicked form and linear form in each lane were quantified, and the relative activity of Topo II $\alpha$ was calculated. The data presented were obtained from triplicate experiments. N, nicked DNA; L, linear DNA; S, supercoiled DNA.

treated with CIP-36 confirmed the morphological observations mentioned above. At a low concentration ( $1 \mu \mathrm{mol} / \mathrm{l}) \mathrm{CIP}-36$ induced the apoptosis of $4.14,8.82$ and $22.25 \%$ of K562/A02 cells after 6, 12 and $24 \mathrm{~h}$, respectively (Fig. 4). The proportion of apoptotic cells increased at a high CIP-36 concentration ( $4 \mu \mathrm{mol} / \mathrm{l}$ ), with $5.4,15.5$ and $35.2 \%$ of K562/A02 cells undergoing apoptosis after 6,12 and $24 \mathrm{~h}$, respectively. These data indicated that the apoptotic effects of CIP-36 occurred in a time- and dose-dependent manner.

Effects of CIP-36 on cell cycle progression. The cells were treated with CIP-36 at the indicated concentrations (1 and $4 \mu \mathrm{mol} / \mathrm{l}$ ) for 6,12 and $24 \mathrm{~h}$, and distinct changes in the cell cycle distribution were observed (Fig. 5). At 6 and 12 h, flow cytometric analysis revealed higher DNA contents (S phase) in the CIP-36-treated cells compared with the controls (treated with DMSO). However, the cells had mainly accumulated in the $S / G_{2}+M$ phase after $24 \mathrm{~h}$. These results suggest that CIP-36 blocks K562/A02 cells in the $\mathrm{S} / \mathrm{G}_{2}+\mathrm{M}$ phase, in contrast to VP-16, which blocks the K562/A02 cells in the $\mathrm{S}$ phase. These findings demonstrate the differences in the mechanisms underlying the antitumor activities of CIP-36 and VP-16.

CIP-36 inhibits Topo II a activity. The novel podophyllotoxin derivative, CIP-36, was examined for its effects on DNA cleavage mediated by human DNA Topo II $\alpha$. We found that CIP-36 increased Topo II-DNA cleavage complex (nicked DNA) levels. Indeed, the DNA bands corresponding to nicked DNA were more intense with 2 or $4 \mu \mathrm{mol} / 1$ CIP-36 (Fig. 6A, lanes 4 and 5). The effects of CIP-36 on DNA cleavage were more prominent than those of the reference compound, etoposide (Fig. 6A, lane 6). The quantification of DNA bands by gel densitometry confirmed these results. CIP-36 increased the 
amounts of nicked DNA while reducing the quantities of linear DNA, in a dose-dependent manner (Fig. 6B).

\section{Discussion}

It is now clear that chemotherapy is indispensable for cancer treatment. However, the occurrence of MDR constitutes one of the main obstacles facing the field of oncology. In this study, we demonstrated that CIP-36 effectively killed not only parental K562 and KB cell lines, but also MDR sublines, such as $\mathrm{K} 562 / \mathrm{A} 02, \mathrm{KBv} 200$ to an equivalent degree. To date, 3 different forms of MDR have been described in more detail: classical MDR, non-Pgp MDR and atypical MDR (22). Atypical MDR has been shown to be associated with quantitative and qualitative alterations in Topo II $\alpha$, a nuclear enzyme that actively participates in the lethal action of cytotoxic drugs. Topo II is an essential enzyme involved in DNA replication and cell division through the cleavage and religation of double-stranded DNA (23). It is known that the expression of this enzyme begins to increase in the late G1 phase, peaks in the G2/M phase and markedly decreases in the G1/G0 phase of the cell cycle $(23,24)$. Topo II exists in 2 forms, namely Topo II $\alpha(170 \mathrm{kDa})$ and Topo II $\beta$ $(180 \mathrm{kDa})$. The $\alpha$ form is highly expressed in proliferating cells, whereas the $\beta$ form is preferentially expressed in cells in the stationary phase $(25,26)$. Several studies characterizing Topo II expression and activity in mammalian cells have demonstrated that the enzyme is more abundant and active in neoplastic cells compared to normal cells (27-29). Therefore, mammalian Topo II has been used as a primary cellular target in the development of several antitumor drugs, such as anthracyclines, acridines, epipodophyllotoxins and amonafide (30). However, the majority of drugs targeting Topo II $\alpha$, including retigeric acid B (31), 19-tert-butyldiphenylsilyl-8, 17-epoxy andrographolide (32) and others (33) have been mainly characterized for conventional cancer cells and those tested in cancer cells with MDR are usually effective only at toxic doses (34), indicating their limited potential in the treatment of MDR cancer types.

In the present study, the novel epipodophyllotoxin derivative, CIP-36, displayed a broad-spectrum activity and exerted significant antitumor activity against the K562 and K562/A02 cells in vitro. Furthermore, the novel drug selectivity inhibited cancer cells, with an $\mathrm{IC}_{50}$ value significantly lower compared with the values obtained for normal cells, including human VECs and fibroblasts (FBs). Of note, we demonstrated that CIP-36 inhibited Topo II $\alpha$ activity, which may explain these findings.

The induction of apoptosis is a strategy used widely in the treatment of cancer (35). Our data demonstrated that CIP-36 induced the apoptosis of the K562/A02 cells in time- and concentration-dependent manner, as demonstrated by Hoechst 33342 staining and flow cytometry. Of note, it has been demonstrated that $5 \mathrm{k}$, a novel $\beta$ - $O$-demethyl-epipodophyllotoxin analogue, is effective against cells with MDR both in vitro and in vivo, albeit inducing apoptotic signaling pathways only at high concentrations of 1.25-5.00 $\mu \mathrm{mol} / 1$ (36).

In conclusion, in the present study, we demonstrated that CIP-36 inhibited Topo II $\alpha$ activity and induced apoptosis, thus inhibiting the growth of multiple cancer cells, including K562/A02 cells with MDR. These findings suggest that CIP-36 has the potential to be used in the treatment of patients with cancers with MDR. Ongoing studies are being carried out in our laboratory for further characterization of this important molecule.

\section{Acknowledgements}

The authors are gratefully to the Great Program of Science Foundation of Tianjin (06YFJZJCO2700) and the Program of Science Foundation of Tianjin (08JCYBJC070000) for financially supporting this study. This study was also supported by a grant from the National Natural Science Foundation of China (no. 30873363).

\section{References}

1. Huff LM, Lee JS, Robey RW and Fojo T: Characterization of gene rearrangements leading to activation of MDR-1. J Biol Chem 281: 36501-36509, 2006.

2. Sinha BK, Kumar A, Bhattacharjee S, Espey MG and Mason RP: Effect of nitric oxide on the anticancer activity of the topoisomerase-active drugs etoposide and adriamycin in human melanoma cells. J Pharmacol Exp Ther 347: 607-614, 2013.

3. Zhu CY, Lv YP, Yan DF and Gao FL: Knockdown of MDR1 increases the sensitivity to adriamycin in drug resistant gastric cancer cells. Asian Pac J Cancer Prev 14: 6757-6760, 2013.

4. Deng S, Yan T, Jendrny C, Nemecek A, Vincetic M, GödtelArmbrust U and Wojnowski L: Dexrazoxane may prevent doxorubicin-induced DNA damage via depleting both topoisomerase II isoforms. BMC Cancer 14: 842, 2014.

5. Miura JT, Johnston FM, Thomas J, George B, Eastwood D, Tsai S, Christians KK, Turaga KK and Gamblin TC: Molecular profiling in gastric cancer: examining potential targets for chemotherapy. J Surg Oncol 110: 302-306, 2014.

6. Smith NA, Byl JA, Mercer SL, Deweese JE and Osheroff N: Etoposide quinone is a covalent poison of human topoisomerase II $\beta$. Biochemistry. 53: 3229-3236, 2014.

7. Pennock GD, Dalton WS, Roeske WR, et al: Systemic toxic effects associated with high-dose verapamil infusion and chemotherapy administration. J Natl Cancer Inst 83: 105-110, 1991.

8. Hartmann JT and Lipp HP: Camptothecin and podophyllotoxin derivatives: inhibitors of topoisomerase I and II - mechanisms of action, pharmacokinetics and toxicity profile. Drug Saf 29: 209-230, 2006.

9. Bender RP, Jablonksy MJ, Shadid M, et al: Substituents on etoposide that interact with human topoisomerase IIalpha in the binary enzyme-drug complex: contributions to etoposide binding and activity. Biochemistry 47: 4501-4509, 2008.

10. Holden JA: DNA topoisomerases as anticancer drug targets: from the laboratory to the clinic. Curr Med Chem Anticancer Agents 1: 1-25, 2001.

11. Osheroff N: Effect of antineoplastic agents on the DNA cleavage/ religation reaction of eukaryotic topoisomerase II: inhibition of DNA religation by etoposide. Biochemistry 28: 6157-6160, 1989.

12. Robinson MJ and Osheroff N: Effects of antineoplastic drugs on the post-strand-passage DNA cleavage/religation equilibrium of topoisomerase II. Biochemistry 30: 1807-1813, 1991.

13. Chen Y, Lin TY, Chen JC, Yang HZ and Tseng SH: GL331, a topoisomerase II inhibitor, induces radiosensitization of human glioma cells. Anticancer Res 26: 2149-2156, 2006.

14. Whang PJ and Huang TS: New trials of GL331, a novel topoisomerase II inhibitor, in treatment of solid tumors. J Intern Med Taiwan 8: 6-11, 1997.

15. Zhang YL, Tropsha A, McPhail AT and Lee KH: Antitumor agents. 152. In vitro inhibitory activity of etoposide derivative NPF against human tumor cell lines and a study of its conformation by X-ray crystallography, molecular modeling, and NMR spectroscopy. J Med Chem 37: 1460-1464, 1994.

16. Liu YQ, Tian J, Qian K, Zhao XB, Morris-Natschke SL, Yang L, Nan X, Tian X and Lee KH: Recent progress on C-4-modified podophyllotoxin analogs as potent antitumor agents. Med Res Rev 35: 1-62, 2015.

17. Chen H, Bi W, Cao B, et al: A novel podophyllotoxin derivative (YB-1EPN) induces apoptosis and down-regulates express of P-glycoprotein in multidrug resistance cell line KBV200. Eur J Pharmacol 627: 69-74, 2010. 
18. Skehan P, Storeng R, Scudiero D, et al: New colorimetric cytotoxicity assay for anticancer-drug screening. J Natl Cancer Inst 82: 1107-1112, 1990

19. Sullivan DM, Glisson BS, Hodges PK, Smallwood-Kentro S and Ross WE: Proliferation dependence of topoisomerase II mediated drug action. Biochemistry 25: 2248-2256, 1986

20. Lemke K, Poindessous V, Skladanowski A and Larsen AK: The antitumor triazoloacridone C-1305 is a topoisomerase II poison with unusual properties. Mol Pharmacol 66: 1035-1042, 2004.

21. Li CH, Chen PY, Chang UM, et al: Ganoderic acid X, a lanostanoid triterpene, inhibits topoisomerases and induces apoptosis of cancer cells. Life Sci 77: 252-265, 2005.

22. Nooter K and Stoter G: Molecular mechanisms of multidrug resistance in cancer chemotherapy. Pathol Res Pract 192: 768-780, 1996.

23. Kellner U, Sehested M, Jensen PB, Gieseler F and Rudolph P: Culprit and victim - DNA topoisomerase II. Lancet Oncol 3: 235-243, 2002.

24. Kimura K, Saijo M, Ui M and Enomoto T: Growth state- and cell cycle-dependent fluctuation in the expression of two forms of DNA topoisomerase II and possible specific modification of the higher molecular weight form in the M phase. J Biol Chem 269: 1173-1176, 1994.

25. Chen W, Qiu J and Shen YM: Topoisomerase II $\alpha$, rather than II $\beta$, is a promising target in development of anti-cancer drugs. Drug Discov Ther 6: 230-237, 2012.

26. Dingemans AM, Pinedo HM and Giaccone G: Clinical resistance to topoisomerase-targeted drugs. Biochim Biophys Acta 1400: 275-288, 1998

27. Priel E, Aboud M, Feigelman H and Segal S: Topoisomerase-II activity in human leukemic and lymphoblastoid cells. Biochem Biophys Res Commun 130: 325-332, 1985.
28. Engstrøm MJ, Ytterhus B, Vatten LJ, Opdahl S and Bofin AM: TOP2A gene copy number change in breast cancer. J Clin Pathol 67: 420-425, 2014.

29. Pendleton M, Lindsey RH Jr, Felix CA, Grimwade D and Osheroff N: Topoisomerase II and leukemia. Ann NY Acad Sci 1310: 98-110, 2014

30. Pourpak A, Landowski TH and Dorr RT: Ethonafide-induced cytotoxicity is mediated by topoisomerase II inhibition in prostate cancer cells. J Pharmacol Exp Ther 321: 1109-1117, 2007.

31. Liu Y, Gao F, Jiang H, et al: Induction of DNA damage and ATF3 by retigeric acid $\mathrm{B}$, a novel topoisomerase II inhibitor, promotes apoptosis in prostate cancer cells. Cancer Lett 337: 66-76, 2013.

32. Nateewattana J, Dutta S, Reabroi S, et al: Induction of apoptosis in cholangiocarcinoma by an andrographolide analogue is mediated through topoisomerase II alpha inhibition. Eur J Pharmacol 723: 148-155, 2014.

33. Zhang X, Bao B, Yu X, et al: The discovery and optimization of novel dual inhibitors of topoisomerase II and histone deacetylase. Bioorg Med Chem 21: 6981-6995, 2013

34. Bau JT, Kang Z, Austin CA and Kurz EU: Salicylate, a catalytic inhibitor of topoisomerase II, inhibits DNA cleavage and is selective for the $\alpha$ isoform. Mol Pharmacol 85: 198-207, 2014.

35. Chen H, Wang J, Zhang J, et al: L1EPO, a novel podophyllotoxin derivative overcomes P-glycoprotein-mediated multidrug resistance in K562/A02 cell line. Biol Pharm Bull 32: 609-613, 2009.

36. Xu D, Cao J, Qian S, et al: $5 \mathrm{k}$, a novel $\beta$-O-demethylepipodophyllotoxin analogue, inhibits the proliferation of cancer cells in vitro and in vivo via the induction of G2 arrest and apoptosis. Invest New Drugs 29: 786-799, 2011. 